\title{
Lasers activate killer instinct in mice
}

Stimulating certain areas of the animals' brains can trigger predatory behaviours including biting and grabbing.

\section{Erin Ross}

12 January 2017

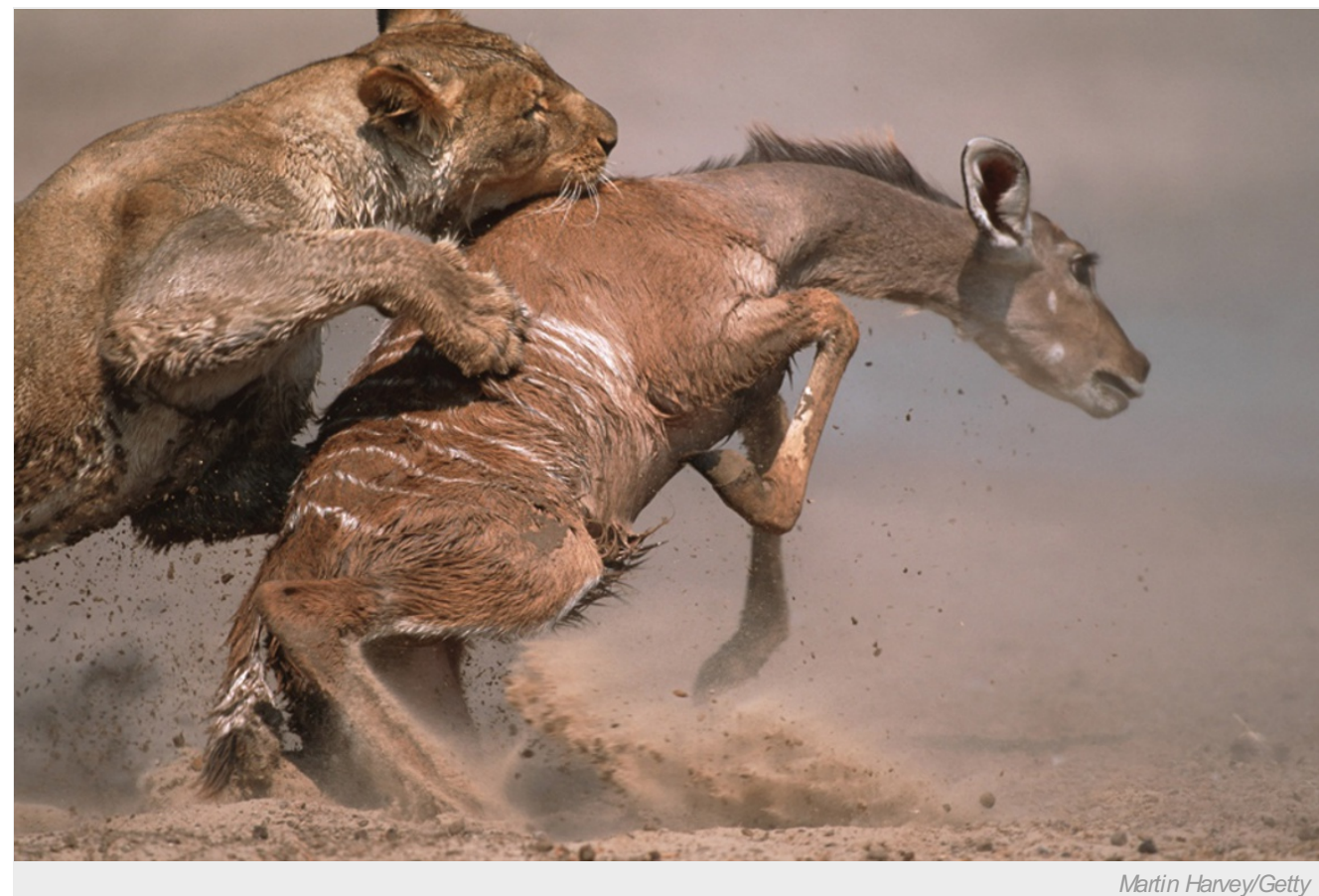

Predatory animals attack and kill their food all the time — but the brain circuits that control such behaviours remain unknown.

Researchers have found a switch that seems to turn on a mouse's predatory instincts. When certain parts of the rodents' brains were stimulated with light, mice displayed a complex array of hunting activities.

Predatory behaviours such as grabbing and biting are familiar to fans of nature documentaries, but the brain circuits involved remain a mystery. Previous research found that the central amygdala, an almond-shaped area of the brain involved in producing emotions including fear, was activated when rats hunt ${ }^{1}$. Researchers wanted to know whether the amygdala itself controls hunting behaviours, and a study published on 12 January in Cell ${ }^{2}$ suggests that it does.

To activate the central amygdala in mice, Ivan de Araujo, a neurobiologist at Yale University in New Haven, Connecticut, and his colleagues used a technique called optogenetics. First, they infected the mice with a virus that made the neurons in their brains sensitive to blue light. Then, the researchers used a tiny optic fibre to shine a blue laser on the amygdala. This prompted the animals to tense their jaw and neck muscles. The behaviour didn't occur when the researchers stimulated other parts of the brain.

When the laser was on, the mice hunted just about everything placed in their paths, from edible treats such as crickets to non-food items like bottle caps. The researchers observed the same activity when they triggered the amygdala with chemogenetics, a similar technique that stimulates neurons with molecules rather than light. The hunting and feeding behaviours even happened when there was nothing to hunt. When mice in empty cages had their amygdalas activated, they stopped whatever they were doing, positioned their front legs as if they were holding food and moved their mouths as if they were chewing.

\section{Friend vs. food}

But this doesn't mean that researchers have found the neural circuit for ravenous, murderous mice, says de Araujo. "The first thing we thought was, maybe this was just generalized aggression. Or maybe we just made the mice very hungry."

So the team tested that. Although the light-stimulated mice hunted more than the ones left alone, both groups ate the same amount. And the laser-activated mice could still tell the difference between friend and food: "When they were with another mouse, they might 
have become more curious, but we didn't observe any attacks," says de Araujo. This left him fairly certain that the experiments were triggering predation, not hunger or aggression.

This is significant because predation is a very complex behaviour, says Kay Tye, a neuroscientist at the Massachusetts Institute of Technology in Cambridge. "It's not just physiological, it's hunting, biting, releasing and eating. Those are motor sequences that require a lot of information, so it's remarkable you can get this behaviour with that sort of gross manipulation."

\section{Opening the door}

Scientists once thought that the central amygdala's role in behaviour was limited to fear. But research has now shown that this area of the brain is implicated in a number of complex behaviours such as grooming ${ }^{3}$. Tye thinks that predation is one more example of the many things it can trigger.

Because the central amygdala is involved in so many different behaviours, she says, future research needs to tease out the precise neuronal circuits involved in hunting. "The central amygdala has been linked to escape and flight — this is completely different from that." A hunting animal is seeking something out for a reward, she explains, whereas a creature in escape or flight mode is actively avoiding something.

Tye wants to know how much overlap there is between the circuits that control the two behaviours. She thinks that the amygdala might be acting as a 'gate', holding back a variety of programmes that are constantly running in the background of the brain. If that's the case, de Araujo and his colleagues may have discovered the door for hunting behaviours.

Nature | doi:10.1038/nature.2017.21292

\section{References}

1. Comoli, E., Ribeiro-Barbosa, É. R., Negrão, N., Goto, M. \& Canteras, N. S. Neuroscience 130, 1055-1067 (2005).

2. Han, W. et al. Cell http://dx.doi.org/10.1016/j.cell.2016.12.027 (2017).

3. Hong, W., Kim, D.-W. \& Anderson, D. J. Cell 158, 1348-1361 (2014). 